\title{
Anemia, CTCAE
}

National Cancer Institute

\section{Source}

National Cancer Institute. Anemia, CT CAE. NCI Thesaurus. Code C143283.

A disorder characterized by a reduction in the amount of hemoglobin in $100 \mathrm{ml}$ of blood. Signs and symptoms of anemia may include pallor of the skin and mucous membranes, shortness of breath, palpitations of the heart, soft systolic murmurs, lethargy, and fatigability. 